\title{
Colloidal processing of Fe-based metalceramic composites with high content of ceramic reinforcement
}

\author{
J. A. ESCRIBANO ${ }^{1}$, B. FERRARI ${ }^{1}$, P. ALVAREDO ${ }^{2}$, E. GORDO ${ }^{2}$, A. J. SÁNCHEZ-HERENCIA \\ ${ }^{1}$ Instituto de Cerámica y Vidrio, CSIC \\ ${ }^{2}$ Departamento de Ciencia de materiales e Ingeniería, Universidad Carlos III
}

\begin{abstract}
Major difficulties of processing metal-matrix composites by means of conventional powder metallurgy techniques are the lack of dispersion of the phases within the final microstructure. In this work, processing through colloidal techniques of the Fe-based metal-matrix composites, with a high content of a ceramic reinforcement $(\mathrm{Ti}(\mathrm{C}, \mathrm{N}))$, is presented for the first time in the literature. The colloidal approach allows a higher control of the powders packing and a better homogenization of phases since powders are mixed in a liquid medium. The chemical stability of Fe in aqueous medium determines the dispersion conditions of the mixture. The Fe slurries were formulated by optimising their zeta potential and their rheology, in order to shape bulk pieces by slip-casting. Preliminary results demonstrate the viability of this procedure, also opening new paths to the microstructural design of fully sintered Fe-based hard metal, with 50 vol. \% of $\mathrm{Ti}(\mathrm{C}, \mathrm{N})$ in its composition.
\end{abstract}

Keywords: iron, carbonitride, titanium, colloidal processing, rheology, slip-casting, metalceramic, suspension.

Procesamiento coloidal de compuestos metalocerámicos en base Fe con alto contenido de refuerzo cerámico Ti(C,N)

Las principales dificultades de procesamiento de materiales compuestos de matriz metálica por medio de técnicas convencionales pulvimetallurgicas es la falta de dispersión entre fases dentro de la microestructura final. Este trabajo describe por primera vez el procesamiento de materiales compuestos de matriz metálica de Fe, con un alto contenido de un refuerzo cerámico $(\mathrm{Ti}(\mathrm{C}, \mathrm{N}))$, mediante técnicas coloidales. El procesamiento coloidal permite un mayor control sobre el empaquetamiento de polvos y una mejor homogeneización de las fases al mezclarse los polvos en un medio líquido. La estabilidad química del Fe en medio acuoso determina las condiciones de dispersión de la mezcla. Las suspensiones de Fe se formularon mediante la optimización del potencial zeta y de su reología, con el fin de dar forma a piezas compactas por colaje en molde de escayola. Los resultados preliminares mostrados demuestran la viabilidad del proceso, además de abrir nuevas vías al diseño microestructural de metales duros de matriz de Fe con un 50 vol. \% de Ti(C,N) en su composición.

Palabras clave: hierro, carbonitruro, titanio, procesamiento, coloidal, reología, colaje, metalocerámico, agua, dispersión.

\section{INTRODUCTION}

In the last few years it has been demonstrated that composite materials, such as the cermets, are the better response to the extreme solicitations in use which are required at several application areas. Research in metal matrix composites is addressed to replace metals, to improve the elastic modulus and the resistance to high temperature, to corrosion and to wear. The incorporation of a ceramic reinforcement in the metallic matrix would provide the cermet the combined properties of metals (ductility and toughness) and ceramic materials (hardness, thermal and chemical resistance), and offers the possibility to tailor the microstructure, according to the specific characteristics of the material (1). The hard metals are a group of cermets, in which the traditional composition is the cemented carbide (WC-Co). These materials have a wide range of applications amongst which is their use as wear parts or cutting tools. Different compositions have been considered for the hard material development, varying under demand both the reinforcement phase and the matrix (2). As reinforcement, the $\mathrm{Ti}(\mathrm{C}, \mathrm{N})$ is mainly used in the manufacture of cutting tools at high temperature (3). There are numerous examples and applications of Fe alloys reinforced by the addition of $\mathrm{TiC}$ (4). However, it has been reported that the use of $\mathrm{Ti}(\mathrm{C}, \mathrm{N})$ as ceramic reinforcement enables the fabrication of a material with better characteristics (5). The development of this kind of Fe-based composites has been strongly motivated by the need of $\mathrm{Co}$ and Ni replacement due to their toxicity.

The conventional powdermetallurgic processing of hard metals shows serious difficulties during the mixing of the phases, due to the low fluidity of the powders. The colloidal processing in aqueous media arises as an alternative, inexpensive and available, to process hard metals. The shaping process should include the formulation of an aqueous suspension that will allow obtaining homogeneous composite materials with complex shapes and structures, minimizing processing defects (6). Consequently, the Fe powders should be highly dispersed in the solvent as well as be maintained chemically stable. The stability of Fe surfaces is related to the interaction particle-particle and particle-medium, which 
determine surface oxidation as well as if networks among particles are attractive or repulsive. Therefore knowledge of the superficial behavior of powders in the suspension medium is a necessary requirement. In a polar medium, such as water, the surface of the non-oxide particles becomes charged due to oxidation/passivation and hydration phenomena, thus the balance between positive and negative sites depends on the electronegativity of the cation of the compound and the $\mathrm{pH}$ of the medium (7). The value of the surface charge of the particles (experimentally determined by the measurement of the zeta potential) will determine the behavior of the suspensions within a range of $\mathrm{pH}$, so that to set flow conditions to cast the slurry, it is also necessary carry out a rheological study to optimize the solid content $(8,9)$.

This manuscript describe the optimization of slurries composed by $\mathrm{Fe}$ and $\mathrm{Ti}(\mathrm{C}, \mathrm{N})$ powders for the colloidal shaping of Fe-matrix cermets with a content of ceramic reinforcement as high as 50 vol. \%. The slip casting has been proposed as shaping technique, since among colloidal processes, the slip casting is the method producing bulk pieces with higher packing densities. An organic molecule, as the citric acid, has been chosen as dispersant to stabilize the suspensions. The citric acid was chosen due to the affinity of the carboxyl groups with metals and its low molecular size, which reduces the water exclusion volume around the particle, and thereby allows preparing slurries with higher solid contents.

\section{EXPERIMENTAL PROCEDURE}

As-received powders were, FeSM (Hugo Haeffner Gruppe, Germany) with $3.40 \mu \mathrm{m}$ of average particle size, a specific surface area of $0.46 \mathrm{~m}^{2} / \mathrm{g}$ and $7.78 \mathrm{~g} / \mathrm{cm}^{3}$ of density, and a $50 / 50 \mathrm{v} / \mathrm{v} \mathrm{TiC} / \mathrm{TiN}$ powder $(\mathrm{Ti}(\mathrm{C}, \mathrm{N})$ Grade C, H.C. Starck $\mathrm{GmbH}$, Germany) with $2.44 \mu \mathrm{m}$ of average particle size, a specific surface area of $3.00 \mathrm{~m}^{2} / \mathrm{g}$ and $5.10 \mathrm{~g} / \mathrm{cm}^{3}$ of density.

The suspensions for zeta potential measurements were formulated with a solid content of $0.1 \mathrm{~g} / \mathrm{L}$ in $10^{-2} \mathrm{M} \mathrm{KCl}$. The $\mathrm{pH}$ was adjusted using HTMA and $\mathrm{HNO}_{3}$. Measurements were carried out using a Zetasizer Nano ZS (Malvern, UK). Rheological behavior of slurries was determined using a Haake Mars rheometer (Thermo Scientific, Germany) with a double-cone plate fix of $60 \mathrm{~mm}$ of diameter and angle of $2^{\circ}\left(\mathrm{DC} 60 / 2^{\circ}\right)$. Test were performed in the control rate mode (CR) shearing from 0 to $1000 \mathrm{~s}^{-1}$ in 2 minutes, dwelling at $1000 \mathrm{~s}^{-1}$ for 1 minute and shearing down to $0 \mathrm{~s}^{-1}$ in 2 minutes. All tests were done at a constant temperature of $23 \pm 0.5^{\circ} \mathrm{C}$. For simplicity without losing significance, in the flow curves presented, only the down-ramps have been plotted.

The suspensions were casted in plaster-of-Paris molds. After drying, the slight contraction of the casted green pieces allows demolding, and then parts with high structural consistency were obtained. For the thermal treatment at $1450^{\circ} \mathrm{C} / 1 \mathrm{~h}$ in ultrahigh vacuum a Carbolite HVT $15 / 50 / 450$ was used. The morphological characterization of the pieces was carried out by direct observation in a field-emission scanning electron microscopy (FE-SEM, TM-1000 microscope, Hitachi, Japan). The density of the green and sintered pieces was determinate by the Archimedes method in mercury and water, respectively.

\section{RESULT AND DISCUSSION}

Colloidal stability of powders of $\mathrm{Fe}$ and $\mathrm{Ti}(\mathrm{C}, \mathrm{N})$ in aqueous media was determined by zeta potential measurements as a function of $\mathrm{pH}$ (figure 1). The Fe powders have an isoelectric point (i.e.p.) of $\mathrm{pH} 4$, whereas the i.e.p. of the $\mathrm{Ti}(\mathrm{C}, \mathrm{N})$ powder occurs at $\mathrm{pH}$ 2.4. For values of $\mathrm{pH}$ above the isoelectric point (i.e.p.), the surfaces of the $\mathrm{Fe}$ and $\mathrm{Ti}(\mathrm{C}, \mathrm{N})$ are negative. Therefore, surfaces of both powders are negative for a wide range of $\mathrm{pH}$. Moreover, both powders reach their highest absolute value of zeta potential for $\mathrm{pH}$ ranging 9-11. The surface charge achieved under these colloidal conditions could provide enough repulsion to prepare stable suspensions by a simple electrostatic mechanism.

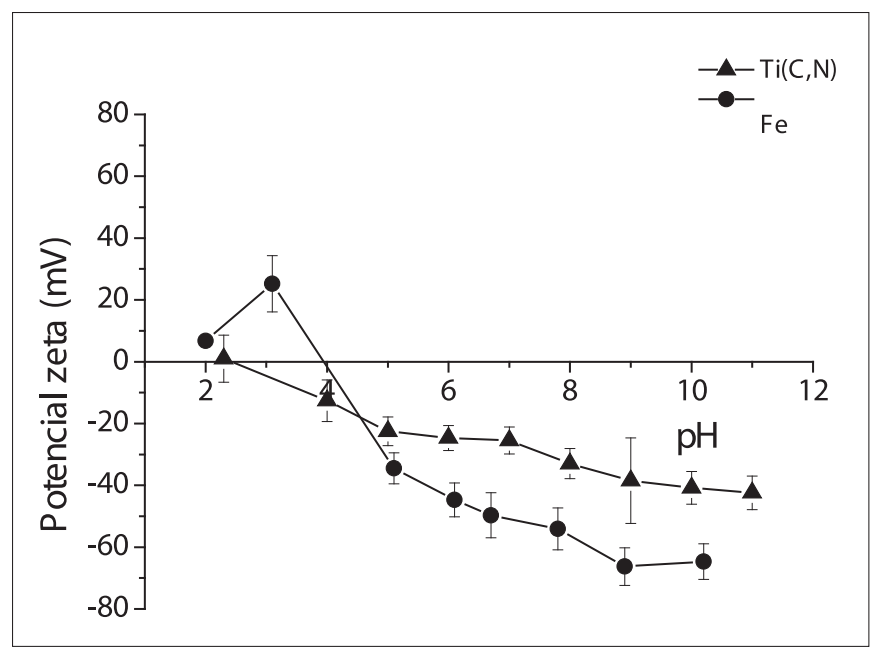

Figure 1. Zeta potential vs. $\mathrm{pH}$ for powders of $\mathrm{Ti}(\mathrm{C}, \mathrm{N})$ and Fe.

It is well known that particles of Fe become oxidized when they were in contact with a polar medium such as water (10). Under certain conditions, the oxidation can be restricted to the particle surface, avoiding the core corrosion and the total particle dissolution. In order to evidence the $\mathrm{pH}$ range where the surface passivation protects the particles core, 10 $\mathrm{g} / \mathrm{l}$ suspensions of Fe were prepared in deionized water at different $\mathrm{pH}$ values, and filtered after 15 days. The wastewaters are shown in figure 2, where different colors can be seen

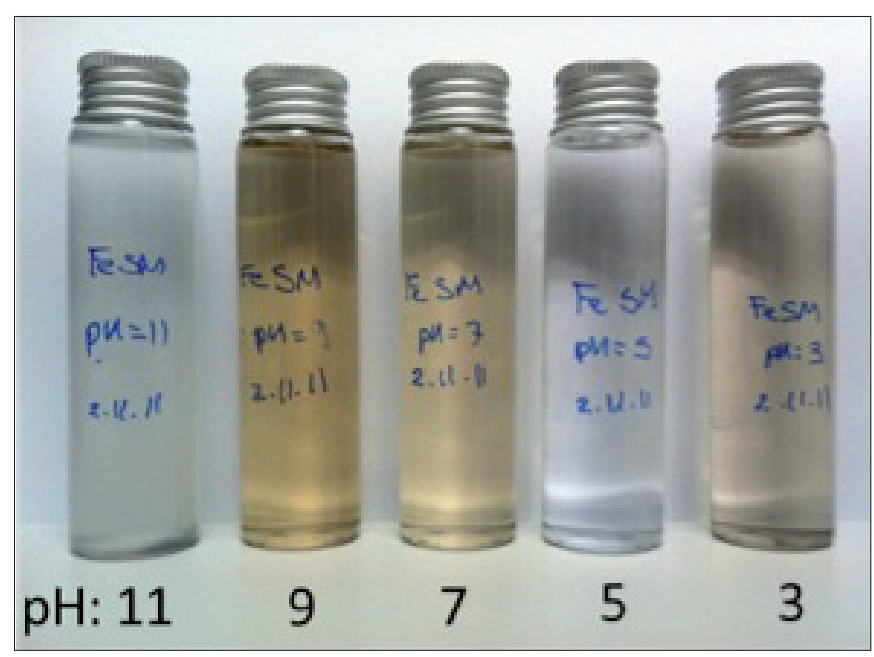

Figure 2. Picture of wastewater showing the Fe oxidation vs. $\mathrm{pH}$. 


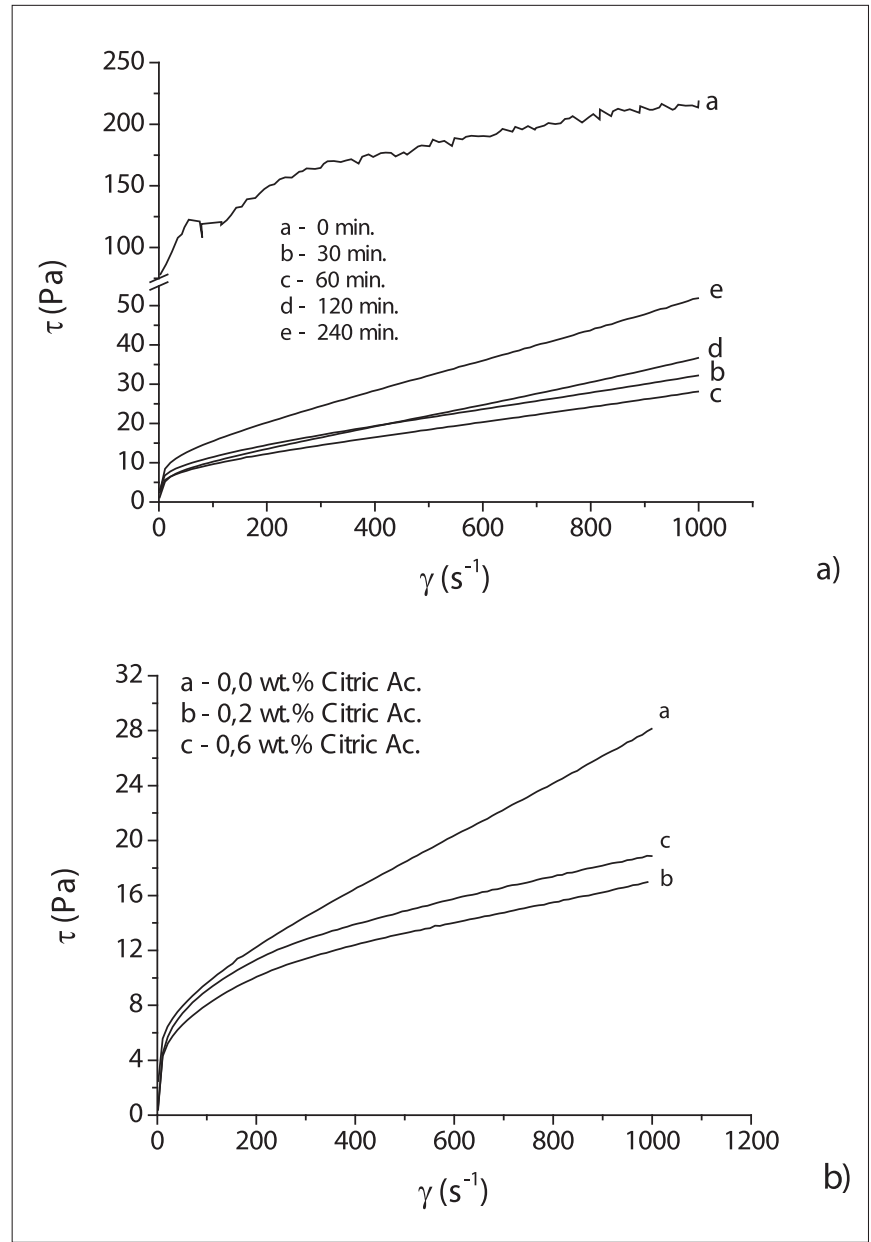

Figure 3. (a) Flow curves of 45 vol. \% suspensions of Fe vs milling time, and (b) flow curves of $45 \mathrm{vol}$ \% suspensions of Fe for citric acid concentrations of 0,0 wt. $\%, 0,2$ wt. $\%$ and 0,6 wt. $\%$.

depending on the amount of $\mathrm{Fe}^{3+}$ dissolved. The wastewater collected from the filtration of the suspension prepared at $\mathrm{pH}$ 11 shows a lower coloration, noting a lower or even inexistent Fe leaching if it is compared with the wastewater collected at other $\mathrm{pH}$. Consequently, $\mathrm{pH} 11$ was selected as working conditions in order to preserve the chemical stability of the system during processing.

Firstly, the rheology of Fe slurries was optimized in agreement with the selected homogenization process. Suspensions were prepared with a solids content of 45 vol. $\%$ at $\mathrm{pH} 11$ adding HTMA, and were milled using nylon balls for times up to $240 \mathrm{~min}$. Figure 3a shows the flow curves registered in the CR test. The Fe slurries exhibit a pseudoplastic behavior and the flow curves evidence the effect that the milling process has in the slurry fluidity. Milling contributes to break the soft agglomerates, which improves homogeneity and consequently, also the fluidity of the slurry. A minimum of viscosity was reaching for a milling time of 60 min, while for longer times of milling viscosity increases. In fact, for long milling times, Fe particles can be deformed by the impact of the milling balls and, modify the rheological behavior of the slurry.

After 60 min of ball-milling, the slurries stabilized at pH 11 has a viscosity below $10 \mathrm{mPa} s$ for shear rates lower than 100 $\mathrm{s}^{-1}$. In order to improve stability and assure flow conditions of the slurries, citric acid was added and then, the slurry was

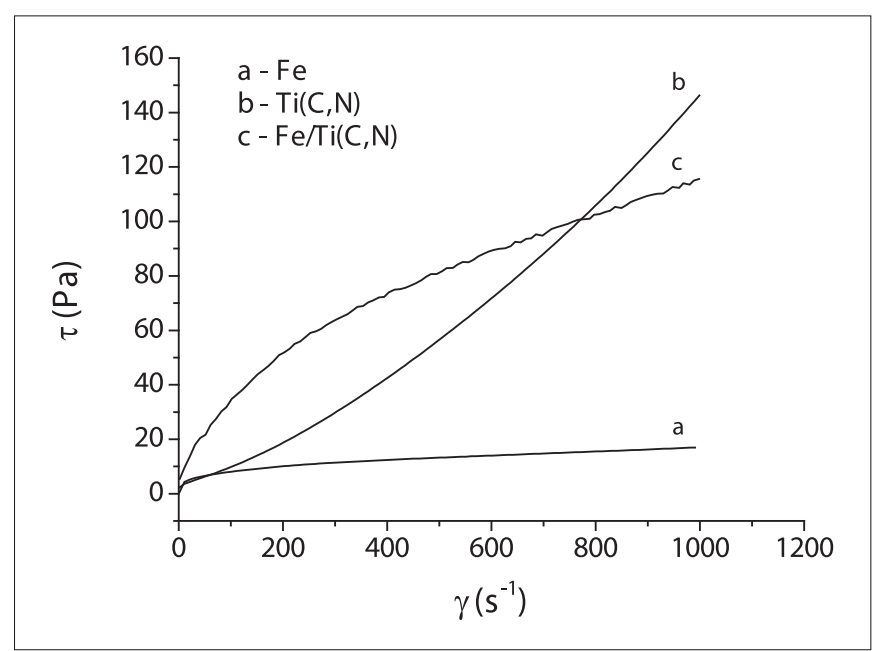

Figure 4 . Flow curves of 45 wt. \% suspensions of Ti (C, N), Fe and Fe/ $\mathrm{Ti}(\mathrm{C}, \mathrm{N}) 50 / 50 \mathrm{v} / \mathrm{v}$ stabilized adding $0.2 \mathrm{wt}$. \% of citric acid.

milled for $60 \mathrm{~min}$. To establish the optimum amount of the stabilizer, the rheology was determined as a function of the added citric acid. Figure $3 \mathrm{~b}$ shows the flow curves of the Fe slurries prepared with 0.2 and 0.6 wt. $\%$ of citric acid, with respect to the amount of powder in the suspension. The flow curve of the slurry prepared without the stabilizer is also plotted, noting that, all curves evidence the pseudoplastic behavior of the Fe slurries. The viscosity decreases with the addition of citric acid, reaching a minimum at the 0,2 wt. \% concentration of the stabilizer. Larger additions slightly increase the viscosity, due to the excess of citric acid dissolved in water that was not adsorbed onto the particle surface, which disturbs the slurry flow.

After determining the optimal conditions for the stabilization of $\mathrm{Fe}$ powders in aqueous medium, slurries of $100 \% \mathrm{Fe}, 100 \% \mathrm{Ti}(\mathrm{C}, \mathrm{N})$ and a mixture $\mathrm{Fe} / \mathrm{Ti}(\mathrm{C}, \mathrm{N})$, were formulated. A similar amount of citric acid was added to stabilize the $\mathrm{Ti}(\mathrm{C}, \mathrm{N})$ slurry. Then the slurry of ceramic powders was dispersed, and homogenized, by milling with $\mathrm{Si}_{3} \mathrm{~N}_{4}$ balls. For the mixture, $\mathrm{Fe}$ and $\mathrm{Ti}(\mathrm{C}, \mathrm{N})$ suspensions were prepared separately and later they were mixed to fit a composition of $50 / 50 \mathrm{v} / \mathrm{v}$ of $\mathrm{Fe} / \mathrm{Ti}(\mathrm{C}, \mathrm{N})$. Figure 4 shows the results of the rheological study for the mixture, compared to the slurries of the constituents. As can be observed the global behavior of the $\mathrm{Fe} / \mathrm{Ti}(\mathrm{C}, \mathrm{N})$ slurry is pseudoplastic, similar to the Fe slurry performance (figure $3 b$ ), but more viscous. The fluidity of the suspension becomes clearly influenced by the behavior of $\mathrm{Ti}(\mathrm{C}, \mathrm{N})$, because of the irregular morphology of ceramic particles (Figure $5 \mathrm{~b}$ ). In fact, the $\mathrm{Ti}(\mathrm{C}, \mathrm{N})$ slurry exhibits a thickening behavior, which is characteristic the flux of the suspensions of particles with a high shape factor and / or compounds with electrically unbalanced lattices (11).

Bulk pieces with a composition of $50 / 50 \mathrm{v} / \mathrm{v}$ of $\mathrm{Fe} /$ $\mathrm{Ti}(\mathrm{C}, \mathrm{N})$ were shaped by slip casting of slurries formulated as described above. After drying, the pieces were characterized by mercury porosimetry and SEM. In figure $5 a$ and $5 b$, the SEM micrographs show the morphology of the starting powders and figure $5 \mathrm{c}$ shows the cross-section of the green bulk pieces of the cermet. The as-received powders of Fe and $\mathrm{Ti}(\mathrm{C}, \mathrm{N})$ exhibit a completely different morphology. Even when powders are within a similar size range (the average particle size ranges from 2.44 to $3.40 \mu \mathrm{m}$ for $\mathrm{Fe}$ and $\mathrm{Ti}(\mathrm{C}, \mathrm{N})$, respectively) and have a wide fraction of fines, the $\mathrm{Fe}$ 

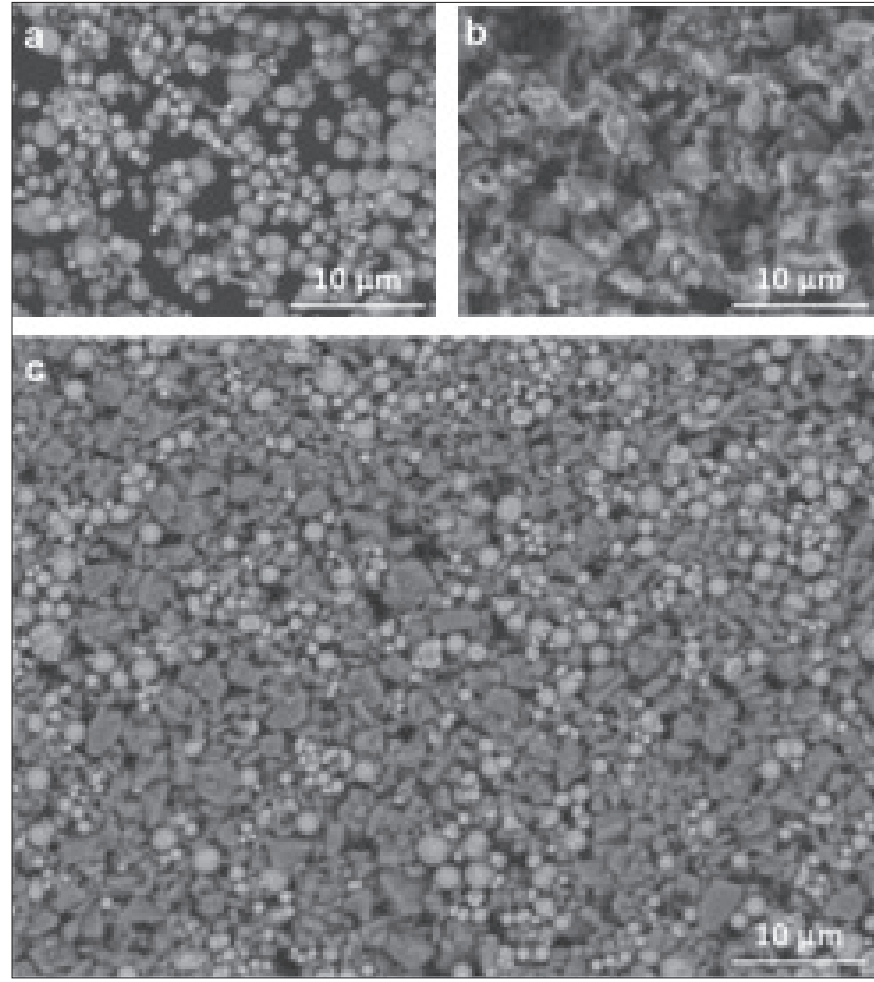

Figure 5. SEM micrographs of (a) as-received Fe powder, b) as-received $\mathrm{Ti}(\mathrm{C}, \mathrm{N})$ powder and c) a cross-section of a $\mathrm{Fe} / \mathrm{Ti}(\mathrm{C}, \mathrm{N})$ green piece.

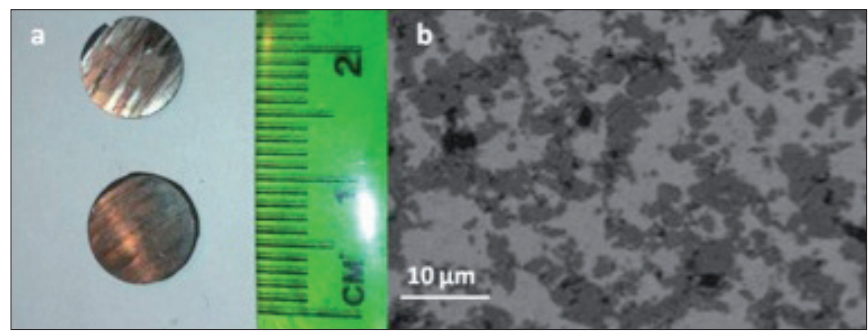

Figure 6. (a) Photograph and (b) SEM micrograph of the bulk pieces and the hard metal microstructure, respectively.

powders are spherical in shape, while the $\mathrm{Ti}(\mathrm{C}, \mathrm{N})$ powders show an extremely irregular morphology. This is the cause of their extremely different rheology (figure 4). But also, due to the morphological difference of the constituent powders, they are easily distinguishable in the micrograph of the mixture. The picture in Figure $5 c$ shows the high degree of homogenization in the composite, which has a density of 52 vol. \% of the theoretical density calculated from the mixtures rule.

Figure 6a shows a picture and a SEM micrograph of a cross section of the cermet after a thermal treatment at $1450{ }^{\circ} \mathrm{C} / 1 \mathrm{~h}$ under high vacuum. Picture shows that bulk pieces of the hard metal have a metallic luster, characteristic on metals, while the micrograph shows the intimate homogenization of the microstructure, where the $\mathrm{Fe}$ and the $\mathrm{Ti}(\mathrm{C}, \mathrm{N})$ phases are mixed at the micrometric scale that is, at the scale of their particle sizes. However, those cermets have a low density $(82 \%)$ due to the lack of packing of $\operatorname{Ti}(\mathrm{C}, \mathrm{N})$ and the low wettability amount $\mathrm{Fe}$ and $\mathrm{Ti}(\mathrm{C}, \mathrm{N})(12)$. Further work should be made to improve the rheology of the ceramic phase and thus, its packing.

\section{CONCLUSIONS}

For the first time the processing of composites $\mathrm{Fe} /$ $\mathrm{Ti}(\mathrm{C}, \mathrm{N})$ with a high content of ceramic phase (50 vol. \%) by colloidal techniques has been described. Processing implies the preparation and stabilization of the Fe particles in aqueous medium. The suspensions of micrometer-sized particles (1-5 microns) of Fe and $\operatorname{Ti}(\mathrm{C}, \mathrm{N})$ were optimized through colloidal studies. For both powders, the maximum dispersion is obtained by electrostatic repulsion at alkaline $\mathrm{pH}(\mathrm{pH} 10$ - 11), at which the corrosion of the $\mathrm{Fe}$ is inhibited by passivation of its surface.

Through rheological studies, slurries with high solids content ( 45 vol. \%) in water, of both a metal and a non-oxide ceramic powder, were formulated. The milling and the addition of a $0.2 \mathrm{wt} \%$ of citric acid, improves the fluidity of the suspensions of the mixture, and allows the shaping of bulk pieces for slip casting (viscosity $<40 \mathrm{mPa}$ s for shear rates $<100 \mathrm{~s}^{-1}$ ) with a green density of $52 \%$. After the thermal treatment at $1450{ }^{\circ} \mathrm{C} / 1 \mathrm{~h}$ in ultrahigh vacuum, the cermet has metallic luster and the ceramic phase is highly dispersed within the metal matrix.

\section{ACKNOWLEDGEMENTS}

Project MAT2012-38650-C02-02 and grant FPI-2010, MINECO (Spain).

\section{REFERENCES}

1. Rosso, M. (2006): Ceramic and metal matrix composites: Routes and properties, J Mater Process Technol, 175 (1-3): 364-375.

2. Li, Y., Liu, N., Zhang, X.,Rong, C. (2008): Effect of WC content on the microstructure and mechanical properties of $(\mathrm{Ti}, \mathrm{W})(\mathrm{C}, \mathrm{N})$-Co cermets, Int J Refract Met Hard Mater, 26 (1): 33-40.

3. Zheng, Y., Xiong, W., Liu, W., Lei, W.,Yuan, Q. (2005): Effect of nano addition on the microstructures and mechanical properties of $\mathrm{Ti}(\mathrm{C}$, N)-based cermets, Ceram Int, 31 (1): 165-170.

4. Aigner, K., Lengauer, W.,Ettmayer, P. (1997): Interactions in iron-based cermet systems, J Alloys Compd, 262-263 486-491.

5. Zhou, S. Q., Zhao, W., Xiong, W. H.,Zhou, Y. N. (2008): Effect of Mo and $\mathrm{Mo} 2 \mathrm{C}$ on the microstructure and properties of the cermets based on Ti(C,N), Acta Metal Sin, 21 (3): 211-219.

6. Hirata, D. Y. (1995): Colloidal processing, Ceramurgia, 25 (5 Faenza, Italy): 271-276.

7. Zhang, J., Duan, L., Jiang, D., Lin, Q.,Iwasa, M. (2005): Dispersion of TiN in aqueous media, J. Colloid Interface Sci., 286 (1): 209-215.

8. Hernández, N., Sánchez-Herencia, A. J.,Moreno, R. (2005): Forming of nickel compacts by a colloidal filtration route, Acta Mater, 53 (4): 919-925.

9. Miao, C., Shen, R., Wang, M., Shafrir, S. N., Yang, H.,Jacobs, S. D. (2011): Rheology of aqueous magnetorheological fluid using dual oxide-coated carbonyl iron particles, J Am Ceram Soc, 94 (8): 2386-2392.

10. Hernández, N., Moreno, R., Sánchez-Herencia, A. J.,Fierro, J. L. G. (2005): Surface behavior of nickel powders in aqueous suspensions, J Phys Chem B, 109 (10): 4470-4474.

11. Ferrari, B., Moreno, R., Lange, F.F. (2000): Comportamiento coloidal de caolín deshidratado, Bol. Soc. Esp. Ceram. Vidrio, 39 (2): 229-235.

12. Alvaredo, P., Gordo, E. (2013): Wettability between iron matrix and $\mathrm{Ti}(\mathrm{C}, \mathrm{N})$ reinforcement of cermets at high temperaure, Euro PM2013 Congress Proceedings, 1: 1-6.

Recibido: $18 / 11 / 2013$

Recibida versión corregida: 20/11/2013

Aceptado: 22/11/2013 